\title{
Study on anthropometric profile of male partners of infertile couples
}

\author{
Teja G.K. ${ }^{1}$, Satyavathi G.A.L. ${ }^{2}$
}

${ }^{1}$ Dr. G. Kanthi Teja, Assistant Professor, ${ }^{2}$ Dr. G. Anantha Lakshmi Satyavathi, Associate Professor; both authors are affiliated with Department of Obstetrics and Gynaecology, GSL Medical College and General Hospital, Rajahmundry, Andhra Pradesh, India

Corresponding Author: Dr. G. Anantha Lakshmi Satyavathi, Associate Professor, Department of Obstetrics and Gynaecology, GSL Medical College \& General Hospital, Rajahmundry, Andhra Pradesh, India E-mail: srujanaivf@gmail.com

\begin{abstract}
Background: Prevalence of obesity and overweight has risen substantially in the past three decades with India ranking third in the number of obese people after USA and china. There was document that the decline in semen quality and male reproductive potential over the past half century may be the result of increasing incidence of obesity. Therefore, present study was made attempt to determine anthropometric profile of male partners of infertile couples. Method: This crosssectional study consisted of 140 male partners of infertile couples aged 18yrs-50yrs, who came to GSL-fertility center, Rajahmundry from 2015 to 2017. Consent was taken from each participant. Ethical reviews and assessments were processed and approved by GSL medical institutional ethical board committee. Data related to individual identification were removed, ensuring the annoying of each individual during the entire study process. With history of mumps, smoking, STDs, prior vasectomy and those taking exogenous hormones were excluded from the study. Result: In the present study sperm concentration more in overweight group, increased concentration with waist circumference and waist-height ratio, inverse relation seen only with waist-hip ratio. Progressive sperm motility showed an inverse relation with BMI, WC, WHR \&WHtR. Slow or non-progressive motility increased with BMI,WC,WHR, also with WHtR with a statistically significant relation. No significant association between anthropometric parameters and sperm morphology. Conclusion: The present study shows no correlation between anthropometry and semen parameters. More studies are needed in this area to clarify the role of body weight and fat distribution on semen quality.
\end{abstract}

Keywords: Anthropometric profile, BMI, Semen parameters, Infertile couples

\section{Introduction}

Infertility is generally defined as one year of unprotected intercourse without conception. Subfertility to describe women or couples who are not sterile but exhibit decreased reproductive efficiency. 85$90 \%$ of healthy young couples conceive within 1 year, most within 6 months. Infertility affects approximately $10-15 \%$ of couples [1]. Overall incidence of infertility has remained relatively unchanged over the past 3 decades. However the evaluation and treatment of infertility have changed dramatically during that time.

Initially infertility was considered primarily a female problem. This notion gave way to the realization that $40-50 \%$ of infertility is wholly or in part due to a male factor. Individual can be categorized as potentially

Manuscript received: $30^{\text {th }}$ June 2019

Reviewed: $10^{\text {th }}$ July 2019

Author Corrected: $18^{\text {th }}$ July 2019

Accepted for Publication: $22^{\text {nd }}$ July 2019 fertile, sub-fertile or infertile. Correct diagnosis and specific treatment can help many infertile men to achieve a natural conception. Mild semen abnormalities can be overcome by treatments such as intrauterine insemination (IUI). When all else is futile or fails, modern assisted reproductive technologies (ART) still may provide the means to achieve success. In vitro fertilization (IVF) by intra-cytoplasmic sperm injection (ICSI) offers men previously considered hopelessly infertile a realistic chance to father children.

Prevalence of obesity and overweight has risen substantially in the past three decades with India ranking third in the number of obese people after USA and china [2]. While much of the focus on the impairments caused by obesity is on somatic health, recent data suggest that reproductive health may also be impacted. This global obesity epidemic parallels a 


\section{Original Research Article}

decrease in male fertility. Many scholarly reports document that the decline in semen quality and male reproductive potential over the past half century may be the result of increasing incidence of obesity[3]. In men, obesity is associated with increased prevalence of azoospermia or oligosospermia [4], decreased semen volume [5], and an increased risk of sperm DNA damage [6].

Consequences of overweight and obesity in Reproductive women have received substantial attention in recent years particularly with reference to PCOS and ovarian reserve. However, the reproductive consequences of excess body weight in men have been studied to a lesser extent [5].

Anthropometry: Anthropometric parameters are commonly used to assess obesity as they are inexpensive, reproducible and can be obtained even in field studies. Various Anthropometric parameters such as BMI, waist circumference, waist hip ratio and waist height ratio are used as research tools for measuring obesity $[7,8]$.

Thus, the aforementioned literature suggests that infertile people can take non-medical measures, such as maintaining body weight and healthy habits, to increase their chances of conception or follow ART. Importantly, most studies evaluating lifestyle-related factors in fertility conditions were conducted in women. Few studies have been conducted on men and, to our knowledge, only one pilot study involving 23 childless couples documented lifestyle factors for both partners [9].

In addition, there is a document that the decline in semen quality and male reproductive potential over the last half-century may be due to an increase in obesity. Therefore, the present study was attempted to determine the physicochemical characteristics of male partners of infertile couples.

Objectives: To determine anthropometric profile of male partners of infertile couples

\section{Material and Methods}

The present cross sectional study consisted of 140 male partners of infertile couples aged 18-50yrs, who came to GSL-fertility center, Rajahmundry was conducted between $1^{\text {st }}$ Oct2015 to $30^{\text {th }}$ Nov 2017. Consent was taken from each participant who fulfills selection criteria. Ethical reviews and assessments were processed and approved by GSL medical institutional ethical board committee. Written informed consent was obtained from all participants.

Inclusion criteria: Male subjects with infertile couples aged $18-50$ yrs

Exclusion criteria: Male subjects with infertile and age more than 50 yrs

Data collection procedure: Data related to individual identification were removed, ensuring the annoying of each individual during the entire study process. Excluding the cases with history of mumps smoking, STDs, prior vasectomy and those taking exogenous hormones.

A pre-structured questionnaire was used to collect the clinical data. Baseline data including age, detailed medical history, past history, family history and personal history was recorded. Clinical examination and routine and relevant investigations was carried out for all participants.

Collection of semen samples- Semen sample was collected via masturbation following 2-4 days of abstinence, into a sterile non-toxic plastic container; sample was liquefied for at least 30minutes to 1 hour prior to performing a routine semen analysis.

Microscopic examination- All semen samples were analyzed for sperm concentration \& motion parameters by hemocytometer (improved Neubauer; Hauser scientific, Inc., Horsham, PA, USA). Sample was diluted in a solution of $0.6 \mathrm{M} \mathrm{NaHco} 3$ and $0.4 \%$ formaldehyde in distilled water. $10 \mu \mathrm{l}$ of well mixed semen was placed on a clean glass slide that had been kept at $37^{\circ} \mathrm{c}$ and covered with a 22 X $22 \mathrm{~mm}$ coverslip, analysis are carried out on a preparation of fixed depth of about $20 \mu \mathrm{m}$. The preparation was placed on the healthy stage of a microscope at $37^{\circ} \mathrm{c} \&$ immediately examined at X400 magnification. Look for aggregation of spermatozoa, agglutination grading, other cellular elements on slide.

Anthropometric parameters-The anthropometric parameters such as weight in $\mathrm{kg}$, height in $\mathrm{cm}$, waist circumference, hip circumference.

BMI was calculated as weight in kilograms divided by height in meters squared. The threshold cutoff values adopted for anthropo-metrical parameters were:

1. BMI - $18.5-24.9 \mathrm{~kg} / \mathrm{m}^{2}$ for normal weight

2. BMI - 25-30 kg/m $\mathrm{m}^{2}$ for overweight

3. BMI - $>30 \mathrm{~kg} / \mathrm{m}^{2}$ for obesity 


\section{Original Research Article}

Waist hip ratio- waist hip ratio calculated as waist circumference divided by hip circumference, both measured to the nearest $0.1 \mathrm{~cm}$ using retractable tape.

Waist height ratio- waist height ratio will be calculated as the waist circumference divided by height.

Waist circumference - $>90 \mathrm{~cm}$ for males

$>85 \mathrm{~cm}$ for females

Waist - Hip ratio $->0.9$ for males

$>0.85$ for females

Waist - Height ratio - >0.53 for both men and women were considered as obesity.

\section{Result}

Table-1: Age distribution

\begin{tabular}{|c|c|c|}
\hline Age group & Frequency & Percent \\
\hline $21-25$ & 27 & 19.3 \\
\hline $26-30$ & 59 & 42.1 \\
\hline $31-35$ & 39 & 27.9 \\
\hline $36-40$ & 12 & 8.6 \\
\hline$>40$ & 3 & 2.1 \\
\hline BMI & & 33.6 \\
\hline $18.5-24.9$ & 47 & 42.9 \\
\hline $25-30$ & 60 & 23.6 \\
\hline$>30$ & 33 & \\
\hline
\end{tabular}

In the present study, out of 140 men age distribution is $21-25$ years, 26-30 years, 31-35 years, 36-40 years and $>40$ years $19.3 \%, 42.1 \%, 27.9 \%, 8.6 \%$ and $2.1 \%$ respectively.

In the present study out of 140 men, according to Indian BMI, 47 (33.6\%) men are categorized as normal (18.5$\left.24.9 \mathrm{~kg} / \mathrm{m}^{2}\right), 60(42.9 \%)$ men are overweight $\left(25-30 \mathrm{~kg} / \mathrm{m}^{2}\right)$ and $33(23.6 \%)$ are obese $\left(>25 \mathrm{~kg} / \mathrm{m}^{2}\right)$

Table-2: Comparison of age \& semen parameters with BMI(body mass index)

\begin{tabular}{|c|c|c|c|c|c|}
\hline BMI & $\begin{array}{c}18.5-24.9 \\
(n=47)\end{array}$ & $\begin{array}{c}25-30 \\
(n=60)\end{array}$ & $\begin{array}{c}>30 \\
(n=33)\end{array}$ & $\begin{array}{c}\text { Total } \\
(n=140)\end{array}$ & P-value \\
\hline Age & 29.04 & 30.18 & 30.85 & 29.96 & 0.201 \\
\hline Semen volume & 1.522 & 1.563 & 1.761 & 1.596 & 0.275 \\
\hline Sperm concentration & 14.621 & 20.660 & 16.191 & 17.579 & 0.291 \\
\hline Progressive & 39.88 & 36.0 & 31.72 & 36.17 & 0.202 \\
\hline Slow/non progressive & 18.07 & 19.49 & 21.56 & 19.55 & 0.252 \\
\hline Immotile & 42.02 & 44.66 & 46.72 & 44.34 & 0.699 \\
\hline \multicolumn{5}{|l|}{ Morphology } & \multirow{3}{*}{0.450} \\
\hline Normal & 6 & 4 & 2 & 12 & \\
\hline Abnormal & 41 & 56 & 31 & 128 & \\
\hline
\end{tabular}

In the present study out of 140 men, most men $(n=60)$ were of overweight $\left(25-30 \mathrm{~kg} / \mathrm{m}^{2}\right)$ group. BMI increases with increasing age, semen volume increases with BMI, sperm concentration is more in overweight group, progressive motility of sperm decreases with increasing BMI, slow, non-progressive motility and immotile sperms increased with BMI, normal morphology decreased with increased with BMI, abnormal morphology raised in over weight group. 
Original Research Article

Table-3: Comparison of age $\&$ semen parameters with wc (waist circumference)

\begin{tabular}{|c|c|c|c|c|c|c|c|}
\hline WC & Age & $\begin{array}{c}\text { Volum } \\
\text { e }\end{array}$ & $\begin{array}{c}\text { Concentrat } \\
\text { ion }\end{array}$ & Progressive & $\begin{array}{c}\text { Slow/non } \\
\text { progressive }\end{array}$ & Immotile & $\begin{array}{c}\text { Morphology } \\
\text { ABN / N }\end{array}$ \\
\hline $\begin{array}{l}<90 \mathrm{~cm} \\
(\mathrm{n}=54)\end{array}$ & 28.65 & 1.532 & 16.828 & 37.63 & 18.02 & 44.35 & 48 \\
\hline $\begin{array}{c}>=90 \mathrm{~cm} \\
(\mathrm{n}=86)\end{array}$ & 30.78 & 1.636 & 18.051 & 35.30 & 20.46 & 44.34 & 80 \\
\hline $\begin{array}{c}\text { Total } \\
(n=140)\end{array}$ & 29.96 & 1.596 & 17.579 & 36.17 & 19.55 & 44.34 & 128 \\
\hline P-value & $\mathbf{0 . 0 0 7}$ & 0.383 & 0.733 & 0.505 & 0.129 & 0.998 & 0.395 \\
\hline
\end{tabular}

In the present study out of 140 men most men $(n=86)$ were of obese group with WC- $>=90 \mathrm{CM}$, as age increases WC increased with a clinical significance $(p-$ value $=.007)$, volume increased in obese group, sperm concentration increased in obese group, but progressive motility decreased with increasing WC, slow/non progressive motility increased in obese group, abnormal morphology equal in both groups.

Table-4: Comparison of Age \& Semen Parameters with WHR (Waist-Hip Ratio)

\begin{tabular}{|c|c|c|c|c|c|c|c|}
\hline$\frac{\pi}{\ddot{z}}$ & 选 & $\begin{array}{l}\stackrel{0}{\Xi} \\
\stackrel{0}{\partial}\end{array}$ & 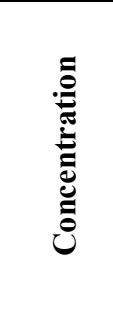 & 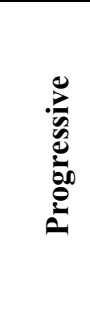 & 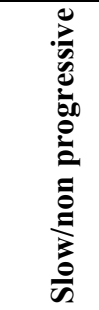 & 总 & 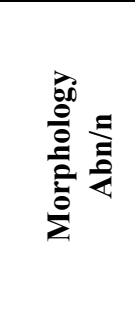 \\
\hline$<0.9(\mathrm{n}=31)$ & 28.13 & 1.494 & 18.961 & 41.45 & 18.21 & 40.34 & 328 \\
\hline $\begin{array}{c}>=0.9 \\
(n=109)\end{array}$ & 30.48 & 1.625 & 17.186 & 34.68 & 19.93 & 45.47 & $9 \quad 100$ \\
\hline $\begin{array}{c}\text { Total } \\
(\mathrm{n}=140)\end{array}$ & 29.96 & 1.596 & 17.579 & 36.17 & 19.55 & 44.34 & 128 \\
\hline P-value & .012 & .351 & .672 & .096 & .359 & .306 & .803 \\
\hline
\end{tabular}

In the present study out of 140 men, most subjects $(n=109)$ were belong to obese group with WHR $>=0.9$. Waist-hip ratio increased with age with statistical significance. Semen volume increased with WHR, concentration of sperm decreased with WHR, progressive motility decreased with increased WHR, immotile and non-progressive sperm motility increased with increased WHR, out of 109 men with raised WHR 9 subjects had abnormal morphology.

Table-5: Comparison of age and semen parameters with WHTR (Waist- Height Ratio)

\begin{tabular}{|c|c|c|c|c|c|c|c|}
\hline & & & & & & \\
\hline
\end{tabular}


Original Research Article

In the present study of 140 men, most subjects $(\mathrm{n}=90)$ were belong to obese group with WHtR- $>=0.53$. With increasing age WHtR increased with clinical significance. Semen volume increased with WHtR, sperm concentration also increased with WHtR, progressive motility decreased with WHtR, slow or non-progressive motility increased with WHtR with clinical significance. Immotile sperms also increased with WHtR, among 90 obese group only 8 subjects were having abnormal morphology.

\section{Discussion:}

In a recent meta-analysis of three largest studies examining the relationship between BMI and sperm concentration came to three completely different conclusions.

A largest study by Aggerholm et al., found no statistically significant relationship whatsoever between BMI and sperm concentration [10].

Jensen et al. found a negative relationship between BMI and sperm concentration [11]. To the contrary Quinn et al, found a positive relationship in their study, where a high BMI was in fact protective against a low sperm count. Although Quinn et al find a positive relationship using simple linear correlation; these results were not consistent across their analyses [12].

Other reasonable large studies found only weak relationship or no relationship at all between BMI and sperm concentration. This was conclusion of Chavarro et al [13] and the study by Koloszar et al [14], reported no significant differences in sperm concentration between men of different BMI categories, relationship in line with their results for sperm concentration.

Magnusdottir et al only found such a relationship in sub-fertile group of men, but not in infertile men [15]. In the present study sperm concentration more in overweight group, increased concentration with waist circumference and waist-height ratio, inverse relation seen only with waist-hip ratio.

Six of seven studies in a meta-analysis included semen volume in parameters. Five out of seven studies including Jensen et al [11], Quinn et al [12] showed no significant relationship with obesity. Only one study, Chavarro et al reported a statistically significant association for semen volume, although these results were not accompanied by any data [13].

In the present study semen volume showed a parallel relationship with obesity parameters. Five studies reported sperm motility as an outcome, with all of these concluding that there is no relationship between BMI and sperm motility, including the tow larger studies investigating BMI and semen parameters $[10,11]$.
In the present study, progressive sperm motility showed an inverse relation with BMI,WC,WHR \& WHtR. Slow or non-progressive motility increased with BMI,WC, WHR, also with WHtR with a statistically significant relation. Only 4 studies reported sperm morphology as an outcome, the largest of these found no significant association between BMI and sperm morphology although results from smaller studies were mixed [11].

In the present study found no significant association between anthropometric parameters and sperm morphology.

Parazzini et al did not find any relationship between BMI and risk of dyspermia, a condition defined similarly to oligoasthenoteratospermia [16]. In contrast Kort et al, found a significant negative relationship between BMI and NMS (normal motile sperm) count [17]. Hammoud et al found a similar trend for the odds ratio of low progressively motile sperm count [18].

These latter studies results indicate that, in terms of BMI related to poorer semen quality in terms of one or more semen parameters.

Two recent meta-analyses explored the relationship between obesity and semen production; however the conclusions of these studies are inconsistent $[19,20]$. Among 31 studies, 5 included in pooled meta-analysis, a total of 6793 men found no significant association between BMI and semen parameters.

Both of these meta-analyses were limited in only assessing general obesity with BMI, and so whatever or not central obesity was correlated with semen quality could not be clarified. Some studies of other anthropometric measures have reported that abdominal fat may be a risk factor for several diseases independent of BMI[11].

Higher WC and HC have been shown to be associated with a lower total sperm count, total motile sperm count and progressive motile sperm count. There is evidence that sperm concentration and total motile sperm count are detrimentally affected by a high BMI and WC $[5,14,21]$. 


\section{Original Research Article}

Several studies have proposed WHR as another proxy for central obesity, correcting the WC for the height of individuals a systematic review suggested that WHR is a more useful global clinical screening tool than WC [22] and a meta-analysis supported the use of WHR in identifying adults at increased cardio-metabolic risk and concluded that WHR appeared to be more useful in Asian than non-Asian population [23].

However in this study the WHR of anthropometric index showed a negative trend with sperm concentration with no statistical significance.

The etiology of relationship between adiposity and sperm production is complex and unclear. Overweight and obesity, and particularly central obesity have been shown to affect the GnRH-FSH/LH pulse, which may impair Leydig cells and Sertoli cell functions and thus interfere with the release of sex hormone and production of mature sperm [18].

As the majority of previous studies have focused only on BMI as the predominant measure of adiposity and not on other anthropometric indexes, our current study is the second to show association between waist circumference, waist-hip ratio and semen parameters. And also first to focus on relationship between waistheight ratio and semen quality in a few number of cases within the general population at a single institute. The meta-analysis of Sermondade, Faure demonstrated that the underweight and obese groups had higher risks of oligospermia and azoospermia [20]. However the results of the current study did not showed a similar relationship.

There were some limitations to this study, it was regretful that we did not have detailed records of endocrine levels, to assist in achieving a greater understanding of the mechanism behind the association between semen quality and obesity. We did not attempt to examine functional parameters such as DNA fragmentation index and seminal oxidative stress. Studies using the DNA fragmentation index as a measure of genetic quality have reported statistically significant positive correlation between BMI and DFI indicating that obesity may still reduce the semen quality even if the sperm count and other sperm parameters remain unchanged $[13,17]$.

In Jorge E Chavarro et al study ejaculate volume was significantly lower in overweight and obese men, and also total sperm count was significantly lower in the group of most obese men [13].
In the present study increased volume in overweight group observed, sperm concentration also showed parallel relation with BMI. In overweight men slightly higher total progressive sperm count than in normal weighted men. In Hammoud et al, Fejes I et al total progressive sperm count decreases with increased adiposity $[14,18]$. In Jensen TK et al, Hammoud et al, Magnusdottir EV et al, Fejes I et al showed lowering of sperm concentration $[11,18,15,14]$. In Aggerholm AS et al,did not find any association [10].

When the present results are included with these past studies, almost just as many studies have reported a null association between overweight and obesity and sperm concentration as have been studies reporting lower sperm concentration with increased body weight. Null findings on other parameters have been more consistent. The present null findings regarding the potential role of BMI on motility and morphology are in agreement with six of seven past studies that have reported on motility. All the previous studies that have reported on morphology similarly consistent, but in contrast with our results have been reports of no association between adiposity and ejaculate volume.

Limitations of the present study: In the previous studies, because results for individual parameters were not reported, it is not possible to know which were affected and complicates interpretation as a significant difference in any one parameter could explain the association with this composite outcome. In the present study considered individual semen parameters. More studies are needed in this area to clarify the role of body weight and fat distribution on semen quality.

There were some limitations to this study it was regretful that detailed records of endocrine levels were not included to assist in achieving a greater understanding of the mechanism behind the association between semen quality and obesity. Authors did not attempt to examine functional parameters such as DNA fragmentation index and seminal oxidative stress.

\section{Conclusion}

Identifying potential modifiable risk factors for subfertility in men may lead to satisfactory and cost effective approach to optimizing fertility treatment such as lifestyle modification. In the present study, no correlation was observed between anthropometry and semen parameters. More studies are needed in this area to clarify the role of body weight and fat distribution on semen quality. 


\section{What the present study adds to existing knowledge?}

Literature on the anthropometric data in male partners of infertility couples has shown different conclusions on role of body weight and fat, which make a meaningful addition in existing literature by conducting the present study in the study area to timely recognition and understanding of common issues related anthropometric data and infertility.

\section{Author's contribution}

Dr. Kanthi Teja: Concept and manuscript preparation

Dr. G. Anantha Lakshmi Satyavathi: Study Design and manuscript preparation

\section{Funding: Nil, Conflict of interest: Nil \\ Permission from IRB: Yes}

\section{Reference}

1. Pasquali R, Patton L, Gambineri A. Obesity and infertility. Curr Opin Endocrinol Diabetes Obes. 2007; 14(6):482-487. doi:10.1097/MED.0b013e 3282f1 d6cb

2. Ng M, Fleming $\mathrm{T}$, Robinson $\mathrm{M}$, Thomson $\mathrm{B}$, Graetz $\mathrm{N}$, Margono $\mathrm{C}$, et al. Global, regional, and national prevalence of overweight and obesity in children and adults during 1980-2013: a systematic analysis for the Global Burden of Disease Study 2013. Lancet. 2014; 384(9945): 766-781. doi: 10.1016/S0140-6736(14) 60460-8. Epub 2014.

3. Cabler S, Agarwal A, Flint M, Du Plessis SS. Obesity: modern man.'s fertility nemesis. Asian J Androl. 2010;12(4):480-489. doi: 10.1038/aja.2010.38

4. Sermondade N, Faure C, Fezeu L, Shayeb AG, Bonde JP, Jensen TK, et al. BMI in relation to sperm count: an updated systematic review and collabo-rative meta-analysis. Hum Reprod Update. 2013; 19(3): 221231. doi: 10.1093/humupd/dms050. Epub 2012

5. Hammiche F, Laven JS, Twigt JM, Boellaard WP, Steegers EA, Steegers-Theunissen RP. Body mass index and central adiposity are associated with sperm quality in men of subfertile couples. Hum Reprod. 2012;27 (8): 2365-2372. doi: 10.1093/humrep/des177. Epub 2012.

6. Dupont C, Faure C, Sermondade N, Boubaya M, Eustache F, Clément $\mathrm{P}$, et al. Obesity leads to higher risk of sperm DNA damage in infertile patients. Asian J Androl. 2013;15(5):622-655. doi: 10.1038/aja.2013.65. Epub 2013.
7. World Health Organization. Physical status: The use of and interpretation of anthropometry, Report of a WHO Expert Committee.

8. Koenker R, Bassett G. Regression quantiles. Econometrika, 46, 33-50. Mathematical Reviews (MathSciNet): MR474644. doi. 1978;10:1913643.

9. Homan G, Litt J, Norman RJ. The FAST study: Fertility ASsessment and advice Targeting lifestyle choices and behaviours: a pilot study. Hum Reprod. 2012;27(8):2396-2404. doi: 10.1093/humrep/des176. Epub 2012.

10. Aggerholm AS, Thulstrup AM, Toft G, RamlauHansen $\mathrm{CH}$, Bonde JP. Is overweight a risk factor for reduced semen quality and altered serum sex hormone profile? Fertil Steril. 2008;90(3):619-626. Epub 2008 20. doi:10.1016/j.fertnstert.2007.07.1292

11. Jensen TK, Andersson AM, Jørgensen N, Andersen AG, Carlsen E, Petersen JH, et al. Body mass index in relation to semen quality and reproductive hormones among 1,558 Danish men. Fertil Steril. 2004;82(4):863870. doi:10.1016/j.fertnstert.2004.03.056

12. Quinn GP, Vadaparampil ST, Gwede CK, Miree C, King LM, Clayton HB, et al. Discussion of fertility preservation with newly diagnosed patients: oncologists' views. J Cancer Surviv. 2007;1(2):146-155. doi: 10. 1007/s11764-007-0019-9.

13. Chavarro JE, Toth TL, Sadio SM, Hauser R. Soy food and isoflavone intake in relation to semen quality parameters among men from an infertility clinic. Hum Reprod. 2008;23(11):2584-2590. doi: 10.1093/ humrep/ den243. Epub 2008.

14. Fejes I, Koloszár S, Szöllosi J, Závaczki Z, Pál A. Is semen quality affected by male body fat distribution? Andrologia. 2005;37(5):155-159. DOI:10.1111/j.14390272.2005.00671.x

15. Magnusdottir EV, Thorsteinsson T, Thorsteinsdottir S, Heimisdottir M, Olafsdottir K. Persistent organochlorines, sedentary occupation, obesity and human male subfertility. Hum Reprod. 2005;20(1):208-215. doi: 10.1093/humrep/deh569

16. Prazzini F, Marchini M, Tozzi L, Mezzopane R, Fedele I. Risk factors for unexplained dyspermia in infertile men: a case-control study. Arch Androl. 1993; 31 (2):105-113. 
17. Kort HI, Massey JB, Elsner CW, Mitchell-Leef D, Shapiro DB, Witt MA, et al. Impact of body mass index values on sperm quantity and quality. J Androl. 2006; 27(3): 450-2. Epub 2005. doi:10.2164/jandrol. 05124

18. Hammoud AO, Wilde N, Gibson M, Parks A, Carrell DT, Meikle AW. Male obesity and alteration in sperm parameters. Fertil Steril. 2008;90(6):2222-2225. doi: 10.1016/j.fertnstert.2007.10.011. Epub 2008.

19.MacDonald AA, Herbison GP, Showell M, Farquhar CM.The impact of body mass index on semen parameters and reproductive hormones in human males: a systematic review with meta-analysis. Hum Reprod Update. 2010;16(3):293-311. doi: 10.1093/ humupd/ dmp 047. Epub 2009.

20. Sermondade N, Faure C, Fezeu L, Shayeb AG, Bonde JP, Jensen TK, et al. BMI in relation to sperm count: an updated systematic review and collaborative meta-analysis. Human Reproduct Update. 2012;19(3): 221-231. doi: 10.1093/humupd/dms050

21. Eisenberg ML, Kim S, Chen Z, Sundaram R, Schisterman EF, Buck Louis GM. The relationship between male BMI and waist circumference on semen quality: data from the LIFE study. Hum Reprod. 2014; 29(2):193-200. doi: 10.1093/humrep/det428. Epub 2013

22. Browning LM, Hsieh SD, Ashwell M. A systematic review of waist-to-height ratio as a screening tool for the prediction of cardiovascular disease and diabetes: 0.5 could be a suitable global boundary value. Nutr Res Rev. 2010 Dec; 23(2):247-69. doi: 10.1017/S09544224 10000144. Epub 2010 Sep 7.

23. Savva SC, Lamnisos D, Kafatos AG. Predicting cardiometabolic risk: waist-to-height ratio or BMI. A meta-analysis. Diabetes, metabolic syndrome and obesity: targets and therapy. 2013;6:403. doi: 10.2147/ DMSO. S34220

\section{How to cite this article?}

Teja G.K, Satyavathi G.A.L. Study on anthropometric profile of male partners of infertile couples. Obs Rev: J obstet Gynecol 2019;5(3):153-160.doi:10.17511/joog.2019.i03.05. 